\title{
Redes sociales en la financiación de la industrialización Antioqueña (1880-1930)
}

\author{
Social networks in the funding \\ the industrialization in Antioquia (1880-1930)
}

\author{
Sioux Fanny Melo León \\ Universidad Externado de Colombia \\ http://orcid.org/0000-0002-2763-7728 \\ sfmelol@gmail.com
}

Fecha de recepción: 30 de julio de 2016

Fecha de aceptación: 28 de noviembre de 2016

\begin{abstract}
Sugerencia de citación: Melo León, S. F. (2017). Redes sociales en la financiación de la industrialización Antioqueña (1880-1930). tiempo\&economía, 4(1), 55-83, doi: http://dx.doi.org/10.21789/24222704.1187
\end{abstract}

\section{RESUMEN}

Este análisis se enfoca en cómo se organizaron los capitales que financiaron la industrialización antioqueña entre 1880 y 1930 y pretende estudiar algunos grupos con diversas relaciones sociales que predeterminaban las relaciones económicas -y que en otro tipo de análisis podrían resultar difusas-. Para tal efecto, se buscaron grupos de personas organizados por su actividad económica (comercio, banca y agricultura), esta categoría ayuda a identificar aquellos sectores de donde provenían los recursos que pudieron trasladarse de otras actividades económicas a la industrialización. Los comerciantes, dado su número, fueron quienes más se involucraron en el proceso de industrialización. Otras actividades económicas aportaron recursos, descartando la hipótesis de que los bancos fueron los financiadores únicos de la industria. Se detectaron relaciones de parentesco trascendentes, pero no fueron las predominantes. 
Palabras clave: redes, historia económica, crecimiento y fluctuación económica, manufacturas y construcción, América Latina y el Caribe

Códigos JEL: L14, N16, N66

\section{ABSTRACT}

This work focuses on how individual capital got together to fund industrialization in Antioquia between 1880 and 1930. This analysis does not take only a person as a subject but also the aggregate that surround this person. This way makes visible some groups whom had different relationships that prearranged economic relationship and in another kind of analysis it would be lost. Searching people appointed by their economic activity helps us to identify some sectors that provided resources to the industrialization process. The commercial sector due to its number of members was the most involved one. In addition, other economic activities put resources, discarding the hypothesis that the bank sector was the only funder in the industry development. The kin relationships were important, but not predominant.

Keywords: Networks, Economic History, Growth and Fluctuations, Manufacturing and Construction, Latin America, Caribbean

JEL Codes: L14, N16, N66 


\section{Introducción}

Colombia, a diferencia de otros países en América Latina, no contaba, a finales del siglo XIX, con una riqueza económica especialmente alta. La región de Antioquia no era la excepción: su aparato productivo no se destacaba particularmente $y$, por tanto, no se pensaba que un desarrollo industrial fuera posible, en especial durante el periodo 1880-1930. Dado que para la época era difícil que una sola persona tuviera todo el capital necesario para llevar a cabo un proyecto de tal envergadura, se presume que debió existir algún tipo de coordinación en la acumulación de capital para formar empresas. Es por esto que vale la pena analizar la forma de financiación que tuvo la industrialización.

En este escrito se busca responder a la pregunta de ¿cómo se juntaron los capitales que financiaron la industrialización antioqueña?. Por medio del análisis de redes sociales, se intentará establecer que estos capitales no solo provienen del café, como se señala ampliamente en la literatura, sino que provienen de diferentes actividades económicas que se encontraban en esta región del país entre 1880 y 1930 . Para esto, se estudiará la cohesión que existe entre redes de actores, lo que permitirá establecer a su vez si dicha cohesión facilitó el flujo de información entre los diferentes sujetos que desempeñaban actividades económicas distintas y si esta información influyó sobre la decisión de colocación de capitales en la formación de empresas, que serían cruciales para la industrialización. El análisis de redes permite ver de forma gráfica la conformación de los grupos económicos y encontrar de manera sintética los posibles financiadores. Así mismo, se pretende ir un paso delante de los análisis estándar en redes sociales empleados en historia: en lugar de estudiar las relaciones alrededor de una sola persona, se revisaron alrededor de un grupo.

Realizando una verificación de la literatura, se encuentra que la primera industrialización antioqueña empieza a finales del siglo XIX con la formación de empresas como la Locería de Caldas (1881) o la Compañía Editorial Antioqueña (1898), entre otros proyectos de esta índole. El periodo en revisión se caracteriza por ser el que corresponde a la fundación de las primeras empresas; aquellas que probablemente fueron absorbidas después por otras más grandes o que debieron cerrar debido a las crisis, pero que, a fin de cuentas, fueron las primeras iniciativas, es decir, las que debieron buscar capital en otras actividades y convencer a los inversionistas para poner sus recursos en algo naciente con un doble carácter propio de la naturaleza de las primeras iniciativas: prometedoras y riesgosas ${ }^{1}$.

Durante este periodo se observa en las ciudades el inicio del empleo de mano de obra sobrante de zonas rurales $y$, con ello, el crecimiento exponencial de zonas urbanas como Medellín, Envigado y Bello, lugares donde estaban situadas las empresas (Ospina, 1987). El caso antioqueño es muy especial, puesto que partió de una sociedad con una baja producción de elementos manuales ${ }^{2}$ y pasó a una que producía buena parte de los productos que antes se importaban. Entre las principales actividades económicas de Antioquia a finales del siglo XVII

1 Se percibe como prometedor debido a que en Europa estas iniciativas habían resultado rentables, pero al mismo tiempo riesgosas, porque no había un mercado establecido para algunos productos y las inversiones hechas en capital o entregadas a un tercero para su manejo podrían perderse.

2 Gran parte de lo consumido en cuanto a manufacturas era importado de otras zonas del país.

tiempo\&economía

Vol. 4 N. ${ }^{\circ} 1$ - I semestre de 2017

p. 57

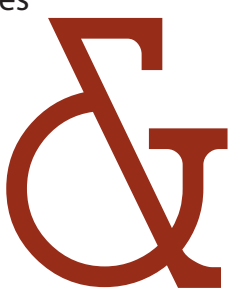


se encuentran la agricultura, la minería y el comercio. Esta última ha sido una de las actividades que ha caracterizado el quehacer antioqueño, incluso desde la conquista.

En su tesis, Safford (1963) hace un estudio de las características de los antioqueños. La denominada pujanza antioqueña estaría relacionada con la falta de mano de obra en la región, ya que en la colonia esta había sido desmantelada por los conquistadores en busca de oro, quienes arrasaron con las comunidades indígenas que fueron prácticamente exterminadas (Poveda, 1982). Esto llevó a que la existencia de instituciones como la mita y la encomienda no fueran tan relevantes como en otras zonas del país. Por esto mismo, en Antioquia la aristocracia $^{3}$ no tuvo cabida y el trabajo fue, desde el inicio, muy apreciado. Esta diferencia de valoración a la observada en el resto del país hizo de los antioqueños (paisas) personas altamente estimadas para trabajar incluso fuera de su región, particularmente en la costa (Brew, 1977). Las cualidades de ser trabajadores y respetuosos de la palabra fueron reafirmadas en los centros de enseñanza, como lo muestra Mayor Mora (1984). Estas cualidades serían importantes más adelante, puesto que en ellas se basarían las relaciones de confianza y negocio que establecerían los actores claves del proceso de industrialización de esta parte del país.

En la parte política, pese a la violencia bipartidista que se evidenció en el país desde la independencia ${ }^{4}$, esta no se observó con tanta fuerza en Antioquia, como lo explica Roldán (2003). Durante el periodo de 1904 a 1930, los partidos políticos tuvieron una "tregua" que en parte empujaría el crecimiento económico. Lo anterior explica por qué el país retrasó parte de su desarrollo, pues la estabilidad política fue alcanzada muy tarde y el hecho de tener una topografía tan segmentada y una lotería de bienes con tan buenos resultados, implicó que no existiera un sólo grupo con la potestad absoluta sobre los recursos y con el poder suficiente para encauzar todo el desarrollo hacia su sector, a diferencia de lo ocurrido en otras naciones suramericanas donde, ya fuera a través del sector minero o agropecuario, tales grupos pasaron a tener el control del país, imponiendo medidas que les favorecieran (Teicheret, 1961; Lipset, y Solari, 1967; Furtado, 1976).

En Antioquia tuvo tanta importancia el comercio y la economía, que pareció existir un pacto tácito entre liberales y conservadores, puesto que siempre se trató de mantener la economía en funcionamiento, incluso durante las guerras (Uribe de H. y López, 2011). Los antioqueños se dieron cuenta de que era más costoso el conflicto que la paz en términos económicos. Este fenómeno se hace más claro luego de la guerra de 1876 (Ospina, 1987), dado que la participación que tuvo el departamento en la Guerra de los Mil Días fue más bien marginal. Esto, sin embargo, no evitó la llegada de tropas dirigidas por personas de otras regiones que tomaron a su paso los recursos que pudieron.

Por tanto, la Guerra de los Mil Días sí tuvo afectó el proceso de industrialización antioqueña: muchas de las iniciativas empresariales que datan de finales del siglo XIX fueron truncadas por la guerra, ya sea porque no encontraron mercado para vender sus productos o porque los ejércitos tomaron parte de los insumos para consumo propio. Al terminar la guerra, quedaron tan marcados en la memoria los efectos de la devastación que resultó más fácil convivir

3 La aristocracia es vista como un grupo de personas dueño de la tierra, pero que no la trabaja directamente.

4 Algunas de las ideas conservadoras o liberales a lo largo del tiempo han ido cambiando tanto de contexto como de banderas y la única forma de distinguirlas es por aspectos tan cotidianos como la religión (Tirado, 1991). 
(confiar) con el afiliado al partido político contrario y hacer negocios con este (Roldán, 2003). Lo anterior demuestra que la guerra facilitó la formación de lazos de confianza que eran totalmente inexistentes antes de esta; lazos que fueron fortaleciéndose con el tiempo. Por tanto, se puede decir que el periodo posterior a la guerra mostró un proceso de crecimiento económico más o menos estable en el departamento.

Desde la perspectiva económica, la mayoría de autores consultados sostienen que el desarrollo de Antioquia se debe principalmente al excedente cafetero (Palacios, 1983; Poveda, 2005; Nieto, 1997; Tirado, 2000; Montenegro, 2002; Ocampo, 2007; Kalmanovitz, 2003). Algunos autores son más específicos en cuanto al aporte cafetero; Arango (1977), por ejemplo, sostiene que más allá del ingreso por las exportaciones está el obtenido por la trilla de café; es decir que el excedente no provenía de la mera siembra y venta de café, sino de las ganancias generadas por el procesamiento del mismo. Así mismo, Arango sostiene que parte de los ingresos cafeteros estuvieron relacionados con el monopolio en la trilla. Es decir, que los excedentes provenientes de esta no volvieron necesariamente a los cultivadores, sino que fueron captados por un grupo que pudo pasar esos recursos a otras actividades.

Ahora bien, el café también puede ser la causa del aumento de demanda interna y del mejoramiento del mercado interno del país, debido a que estos recursos impulsaron la construcción de vías férreas que conectaron diversas regiones de la nación en el afán por sacar más rápidamente el producto al exterior (Palacios, 1983; Tirado, 2000; Montenegro 2002). La colonización antioqueña implicó, además, que buena parte de la producción de café, y sus respectivas ganancias, estuviera en manos de muchos pequeños propietarios quienes, a su vez, estaban en capacidad de demandar más bienes. Es así como los comerciantes entran a proveer la demanda. Otros autores como Poveda (1979), Tirado (2000), Arango (1977), Kalmanovitz (2003) y Restrepo (2011) sugieren que los comerciantes pasaron a ser industriales, reemplazando parte de lo que importaban para producirlo ellos mismos, convirtiéndose en parte importante de la industrialización.

No obstante, el flujo de capitales no se presentó únicamente en la industria del café. También sucedió en la explotación de minas, como sostienen Restrepo (2011), Cuervo y González (1997), Poveda (1984) y Ospina (1987). En Antioquia se encuentra el caso de la mina El Zancudo, que durante mucho tiempo generó bastantes rentas, las cuales poco a poco fueron entrando al mercado por medio de la diversificación de inversiones. Es de destacar que además de la promoción de capitales, la minería representó algo más para la industria: un primer ejercicio que les enseñó la manera de asociarse y les dio idea de cómo funcionaban las sociedades anónimas (Tirado, 2000). Pese a que la sociedad anónima fue la forma preferida de asociación, también lo es la incorporación económica de familias que crearon empresa, como lo mencionan Poveda (1979) y Montenegro (2002).

Algunos autores hacen ver que el modo en que fluyeron los capitales de la minería a la industria se dio por medio de los bancos, dado que estos distribuían los recursos a las industrias que necesitaban algún tipo de apalancamiento (Kalmanovitz, 2010; Poveda, 1979; Tirado Mejía, 2000; Arango, 1977).

Teniendo en cuenta las posturas anteriores sobre los procesos de actividad y financiamiento de la industrialización antioqueña, es interesante conocer la manera como se articulan los grupos que hacían parte de las actividades económicas mencionadas anteriormente y el tipo 
de relaciones que sostenían, para así comprender mejor los condicionantes socioeconómicos que permitieron la unión de capitales en este periodo y, con ello, la primera industrialización antioqueña. Buscando entender el fenómeno, se deben tener en cuenta los procesos de industrialización en otros lugares del mundo, así como algunas conclusiones acerca de lo que sucede en este proceso.

Gerschenkron (1970) sostiene que la industrialización es un proceso evolutivo: en la medida en que tiene características de lo que ha sucedido en el pasado, cada nuevo proceso toma un camino distinto y, por tanto, cada industrialización es completamente diferente en el país dónde se da. En otras palabras, ese proceso evolutivo implica que para aquellos que decidieron dar el paso por primera vez, no fue tan costoso ni tan difícil obtener el capital necesario, mientras que los siguientes debieron conseguir una suma cada vez más alta para ser competitivos frente a aquellos que ya habían acumulado la experiencia y el capital.

Los procesos de industrialización tienen dos aspectos importantes: innovación y financiación (Landes, 1979). La innovación tiene en cuenta los cambios necesarios, ya sea a gran o pequeña escala. Posiblemente los primeros de este estilo, como lo mencionó Adam Smith (1776), están relacionados con la división de trabajo y la productividad del mismo. Para el caso colombiano, siguiendo a Gerschenkron (1970), la cantidad de capital necesario para la industrialización debía ser más alta que la empleada por los ingleses o alemanes cuando empezaron la revolución, porque para el momento en que empezó la industrialización en Colombia, las iniciativas estaban muy rezagadas del resto del mundo y alcanzar la tecnología para ser competitivos $^{5}$ como los pioneros internacionales implicaba una mayor inversión de capital. Para el caso antioqueño, el funcionamiento de sociedades comerciales fue la mejor solución durante este proceso. Esto explica por qué era necesario hacer algún tipo de sociedad para alcanzar las elevadas sumas necesarias para lograr un proceso de industrialización. En Colombia, buena parte de las iniciativas empezaron a baja escala y sin posibilidad de competir con otros mercados, pero a medida que se fueron ampliando las perspectivas, fue común el cambio de dueños en las empresas. Esto fue tan evidente, que ya para 1910 hubo un auge empresarial que en buena medida se puede atribuir al cambio de dueños en las empresas (Tovar, 1989). Es decir, las empresas dejaban de ser propiedad de una persona o familia para ser de un grupo de personas que buscaban, ante todo, diversificar riesgos.

En la literatura, cuando se habla específicamente de industrialización se menciona a aquellos que hicieron las primeras fábricas; de hecho, hay bibliografía que narra la manera como las uniones entre diferentes grupos y familias formarían las primeras empresas sólidas antioqueñas (Botero, 2003; Dávila, 2012). Este fenómeno de desarrollo a partir de la unión entre la élite de una región no es aislado, se presentó de la misma forma en Suráfrica (Verhoef, 2008) y México (Musacchio y Read, 2007).

Luego de la revisión de bibliografía, es claro que la industrialización antioqueña fue un proceso construido por varios grupos, si se le observa desde los ejercicios económicos de sus ejecutores, pero en todos estos análisis no es evidente la manera como los recursos pudieron fluir de otras actividades a la industrialización antioqueña; por tanto, se propone hacer un acerca-

5 Para este caso, la competitividad no se refiere a la eficiencia en producción o menores precios en el mercado internacional, sino al local. Las industrias nacionales nacientes tenían a su favor que los extranjeros debían pagar altos costos en transporte para llevar sus productos a los demandantes finales. 
miento a este fenómeno por medio de la metodología de redes sociales. Esta metodología no solo tiene la ventaja de poner en forma gráfica los relacionamientos que se encuentren en el análisis, también permite medir los niveles de interacción entre diferentes conglomerados de personas.

Para el caso de estudio, las redes permitirían observar la concurrencia en las empresas de un grupo de personas dependiendo si estas también se relacionaban con otras que ejercían la misma actividad económica, partiendo del supuesto que primero desarrollaron negocios que tradicionalmente se daban en el territorio para luego establecer alianzas con otros con el fin de crear o invertir en nuevas industrias. De esta forma, se busca examinar los conglomerados económicos hasta tratar de reconocer los grupos en diversas actividades que hicieran traslado de fondos en el periodo 1880-1930.

El escrito está divido en tres secciones: en la primera se explicará el modo en que se conformaron las redes y su análisis. En la segunda se hacen algunas explicaciones sobre las medidas realizadas en las redes, y en la tercera se dan las conclusiones del trabajo.

\section{Redes sociales en la industrialización}

Los análisis de redes sociales son comunes en estudios de sociología donde se busca conocer la composición de un grupo de personas y saber cómo las interacciones entre los individuos crean la unidad del grupo en estudio. Granovetter (2005) señala en sus análisis de sociología económica que a través de las redes sociales se generan vínculos económicos que refuerzan la existencia de las mismas.

La hipótesis que se plantea en este artículo es que entre los grupos de actividad económica común existía circulación de información, lo que hacía más fácil saber si un negocio era rentable o no; este hecho puede medirse a través de la densidad de la red ${ }^{6}$. Junto a esta información está la posibilidad de establecer alianzas que se hacen visibles con la participación conjunta en la conformación de las empresas. De esta forma se encuentran los actores centrales ${ }^{7}$ en cada una de las redes. Estos circulaban de mejor manera la información y, al mismo tiempo, tenían mayores recursos para invertir en más empresas. Otro aporte que se puede realizar desde el análisis en redes es la capacidad de diversificación que tenían los agentes al considerar su buena visión para los negocios (especialmente en aquellos que podrían generar riesgo) y su capacidad de contar con una alta cantidad de capital disponible para poder invertir en diferentes proyectos al mismo tiempo.

6 Este hecho supone que la confianza, así como la circulación de información, está relacionada con la pertenencia a una misma empresa.

7 Pese a que hay algunos autores (Burt, 1992; Goyal y Vega-Redondo, 2007) que señalan los agujeros estructurales como una forma más eficiente de estudiar conglomerados y personas que conectan grupos, para este caso se busca conocer agrupaciones de personas coincidentes. Probablemente un análisis posterior a este artículo debería ser una agrupación por clústeres. La importancia de reconocer actores con altos valores de centralidad está en buscar formas de diversificación y la tenencia de mayores recursos.

tiempo\&economía Vol. 4 N. ${ }^{\circ} 1$ - I semestre de 2017 
Para efectos de este trabajo, el análisis en redes se divide en cinco partes: red de personas con acciones de bancos o sociedades comerciales con funciones de banca ${ }^{8}$, red de banqueros industriales, comerciantes industriales, agricultores industriales $y$, finalmente, todos los industriales. Esta última red de actores incluye a todos los empresarios y sus relaciones en empresas. Dicha red mostraría en promedio la cantidad de conexiones que tendría cada uno de los empresarios, evidenciando además el nivel de diversificación que tendrían los agentes. Se revisará si esta cumple con las estadísticas correspondientes a la medidas de centralidad en redes sociales (Ruhnau, 2000). Se hicieron, además, otros análisis sobre las redes de minería y urbanización, cuyos resultados no se muestran en este escrito debido a que su relevancia sobre el total es muy poca.

Las redes sociales se formaron a partir de fuentes secundarias: libros y biografías de personas que pertenecieran a ese periodo, especialmente literatura que reproduce las escrituras de creación de las empresas. La tabla 1 muestra los libros de los que se obtuvieron los datos empleados en el análisis. Inicialmente se tomaron todas las empresas y personas que corresponden al periodo de estudio (1880-1930) y que aparecieran en la bibliografía relacionada en la tabla mencionada. Luego se filtró la información por año de creación de la empresa9. Este análisis tiene como limitación que no se cuenta con el valor o monto que aportaba cada socio dentro de la industria y, por tanto, no se puede establecer jerarquía por porcentaje de pertenencia, sin embargo vale recordar que el fin de este análisis es verificar la diversificación del capital en sectores y no la propiedad de las empresas. En algunos casos se contó con la transcripción de la escritura pública de creación de la empresa, mientras que en otros solo se contó con la mención de la creación y los socios presentes en la misma.

Tabla 1. Bibliografía empleada en la construcción de las redes

\begin{tabular}{|c|c|c|}
\hline $\mathbf{N}^{\circ}$ & Autor & Título \\
\hline 1 & Botero (2003) & La industrialización en Antioquia: génesis y consolidación, 1900-1930 \\
\hline 2 & Valencia (2003) & $\begin{array}{r}\text { El empresario en el antiguo Caldas (1850-1930). En C. Dávila, } \\
\text { Empresas y empresarios en la historia de Colombia. Siglos XIX-XX. Una } \\
\text { colección de estudios recientes }\end{array}$ \\
\hline 3 & Álvarez (2003) & $\begin{array}{c}\text { De las sociedades de negocios al "Sindicato Antioqueño". Un camino } \\
\text { centenario. En C. Dávila, Empresas y empresarios en la historia de } \\
\text { Colombia. Siglos XIX-XX. Una colección de estudios recientes }\end{array}$ \\
\hline 5 & Brew (1977) & $\begin{array}{r}\text { El desarrollo económico de Antioquia desde la independencia } \\
\text { hasta 1920 }\end{array}$ \\
\hline
\end{tabular}

8 Más adelante, la composición de estas sociedades bancarias y comerciales ayudará a conocer quienes invertían de manera indirecta en las empresas, puesto que entre los dueños de empresas había incluso algunos banqueros.

9 El periodo de tiempo se estableció durante la revisión de literatura y la construcción de la base de datos, pues se empezó a notar que posterior a 1930 hubo cambio en las juntas directivas y absorción de empresas dedicadas al mismo producto. 


\begin{tabular}{|c|c|c|}
\hline No & Autor & Título \\
\hline 6 & Molina (2006) & Empresarios colombianos del siglo XIX \\
\hline 7 & Echavarría (2008) & Crónicas e historia bancaria de Antioquia \\
\hline 8 & $\begin{array}{c}\text { Grupo de Historia Empresarial } \\
\text { EAFIT (2013) }\end{array}$ & $\begin{array}{c}\text { Fuentes documentales para la historia empresarial: la industria } \\
\text { de Antioquia, 1900-1920 }\end{array}$ \\
\hline 9 & Botero (1996) & Medellín 1890-1950: Historia Urbana y juego de intereses \\
\hline 10 & Botero (2007) & $\begin{array}{l}\text { La ruta del oro: una economía primaria exportadora: Antioquia, 1850- } \\
\qquad 1890\end{array}$ \\
\hline 11 & $\begin{array}{c}\text { Grupo de Historia Empresarial } \\
\text { EAFIT (2006) }\end{array}$ & $\begin{array}{l}\text { Fuentes documentales para la historia empresarial, Tomo I, Siglo XIX en } \\
\text { Antioquia }\end{array}$ \\
\hline 12 & Botero y Alberto (2006) & Medellín. República de Colombia \\
\hline
\end{tabular}

Fuente: elaboración propia.

La característica que determinó la existencia de una relación es la coincidencia del nombre dentro de la escritura de una empresa; así, se puede determinar que ambos agentes en una relación son socios o fueron socios en algún momento o si tuvieron acciones en una misma empresa. Cada una de las relaciones está expresada dentro de la red ${ }^{10}$ como una arista; estas a su vez expresan el peso de la relación, es decir, si dos personas se encuentran en más de una empresa, su arista en proporción será más gruesa que la de aquellos que tan solo se asocian a una. Por construcción, la red tiene relaciones entre el mismo conjunto, por lo que es una red a un modo. Así mismo, dada la definición de la relación, es imposible que existan las relaciones entre una misma persona. Como solo se toma la existencia de la relación sin importar connotaciones positivas o negativas, la red es no valuada (una explicación más precisa de la herramienta se encuentra en el Anexo 1). En resumen, la red que aquí se presenta es a un modo, no dirigida, con pesos, no valuada y no contiene autointeracciones.

Para realizar los grafos se empleó el software Gephi ${ }^{11}$. Aunque algunos cálculos fueron elaborados con este software, otros fueron realizados por la autora. La mayoría de grafos fueron creados empleando un arreglo tipo Force Atlas, que busca ordenar los nodos dependiendo de la probabilidad de ocurrencia de aristas en un mismo grupo de nodos. Debido a la necesidad de encontrar concurrencia de grupos de personas, esta organización del grafo era de gran ayuda en la identificación de personas y su grupo allegado. En todos los casos el tamaño del nombre del nodo está relacionado con el tamaño del mismo, dependiendo de la medida que muestre; dado que en el último grafo, poner los nombres volvía difícil la lectura este no tiene nombres asociados.

Teniendo en cuenta las explicaciones anteriores, se procedió a realizar la búsqueda bibliográfica donde, en un primer momento, se identificaron los personajes que tuvieran actividades económicas en los siguientes sectores: agropecuario, banca, comercio, minería y urbanización. Posteriormente se investigó la composición de algunas sociedades comerciales y bancarias, puesto que estas eran las dueñas del capital que fue puesto a modo de inversión en algunas empresas. Terminado este proceso, se prosiguió a realizar una red de relaciones comerciales por medio de verificación de las personas que pertenecieron al sector agropecuario

10 Desde la terminología matemática, la forma gráfica de una red es el grafo de la misma.

11 https://gephi.org/

tiempo\&economía

Vol. 4 N. ${ }^{\circ} 1$ - I semestre de 2017 
y que hicieron parte de alguna junta de una empresa, ya fuera de manera directa o indirecta ${ }^{12}$. El mismo procedimiento se realizó para los demás sectores mencionados líneas arriba y, finalmente, se estableció la red completa de industriales antioqueños para el periodo 1880-1930 teniendo en cuenta las características de cada grupo. Pese a que se utilizó la información de pertenencia a empresas y sociedades comerciales, los nombres de estas no aparecen porque fueron reemplazados directamente por los nombres de las personas que las componían, hecho que es de interés para el presente estudio.

\section{Gráfico 1. Grafo del esquema general de la composición del grupo de actores en cada una de las actividades económicas}

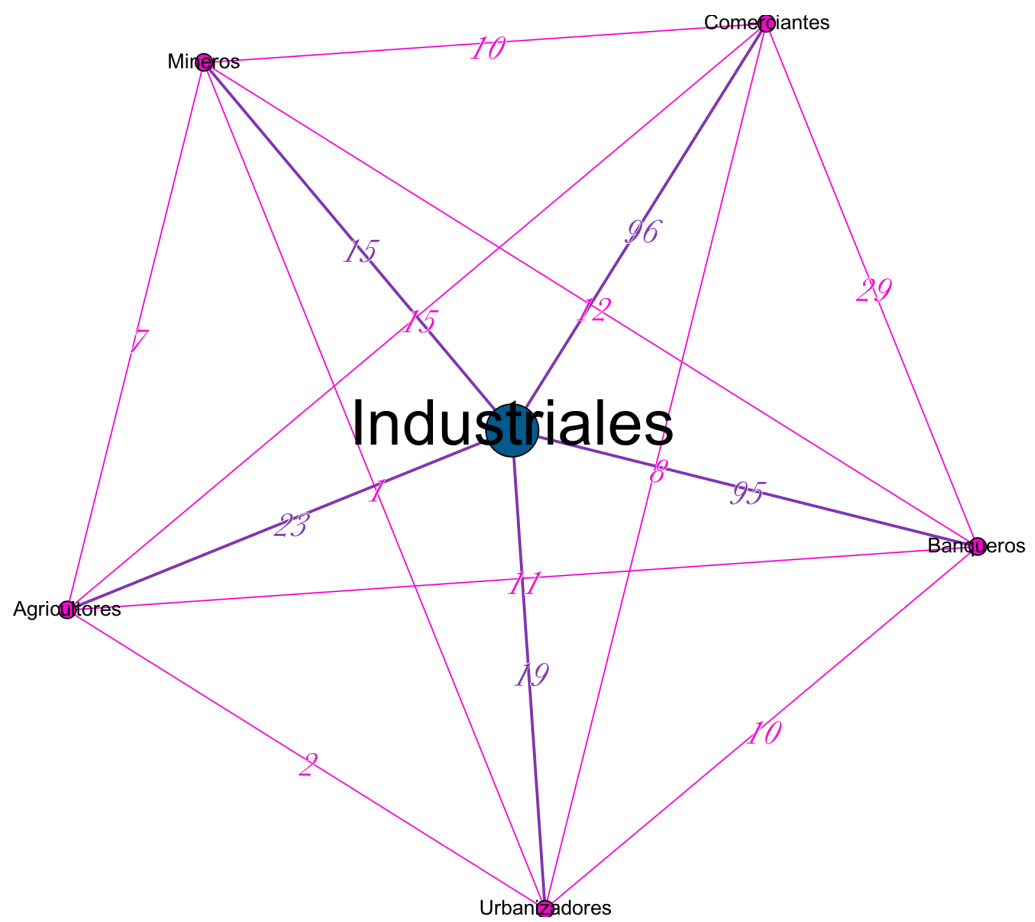

Fuente: elaboración propia.

El gráfico 1 es el esquema de los grupos económicos estudiados: sobre las aristas se encuentra el número de agentes o nodos que comparten los grupos según su afiliación a un grupo económico o que se dedican a esas actividades. En su mayoría, los comerciantes y banqueros están relacionados en mayor medida con la industrialización. También se encuentra que entre comerciantes y banqueros existe una mayor cantidad de nodos que los que se presentan entre las otras actividades.

12 Se determina que una inversión directa es aquella que se hace por medio de una sociedad comercial o bancaria, debido a que la red es a un modo, las asociaciones se multiplicaron por el número de personas que hacían parte de esa sociedad comercial o bancaria. Las relaciones de tipo indirecto tienen el mismo tratamiento que las relaciones de tipo directo. El hecho de no tener montos en las relaciones hace que este proceso sea más fácil y, además, da la ventaja de permitir "desenmascarar" a personas con múltiples negocios bajo otras firmas. 


\section{Bancos antioqueños}

El análisis de bancos se hizo en dos partes: relaciones comerciales entre dueños de bancos y relaciones comerciales entre empresarios que, al mismo tiempo, eran banqueros. En este apartado se hace un análisis de las relaciones ${ }^{13}$ que había entre los dueños de los bancos. Como se mencionó anteriormente, este estudio puede tener cierto sesgo debido a que no se contó con el valor exacto de la suma de dinero que cada uno de los capitalistas poseía ${ }^{14} \mathrm{o}$ tenía invertido en cada empresa, banco o sociedad a la que pertenecía. Es decir, un banquero pudo tener una alta suma de dinero entre sus haberes, pero únicamente lo tenía invertido en el banco de su propiedad; por lo tanto, no se destaca su importancia como banquero y, en consecuencia, su nombre no sobresale dentro del análisis.

Vale la pena aclarar que algunos bancos y entidades bancarias no existieron al mismo tiempo: algunos tuvieron larga vida, mientras que otros se vieron afectados por la Guerra de los Mil Días o la crisis de 1929. La importancia de evaluar esta red es conocer algunos de los accionistas que posteriormente se verán relacionados en las empresas, sea como bancos en sí mismos o como casas comerciales. En la existencia de bancos es importante tener en cuenta que los bancos colombianos tuvieron un momento en que podían hacer emisiones de papel moneda a título propio. Sin embargo, la existencia del Banco Nacional propuesta por Núñez (Sastoque, 2014) hizo que estas emisiones se detuvieran por un tiempo; luego de ser suspendida esta medida, los bancos volvieron a emitir su propio papel moneda. Esto explica por qué hay un periodo en el que no hubo formación de bancos.

El paso a la banca libre permitió que la economía fuera más flexible en cuanto a medios de pago, cubriendo de cierta forma la escasez de metálico que hubo en algunos periodos (Álvarez y Tomoté, 2011). Buena parte de los bancos reseñados hicieron parte de la banca libre antes y después de los primeros intentos de banca central, estos bancos tenían funciones de banca y casas comerciales siendo, en el mejor de los casos para Antioquia, una forma de diversificar las altas ganancias obtenidas en actividades como el comercio y la minería (Correa, 2009).

El gráfico 2 muestra la red de banqueros, con 122 nodos y 680 aristas. A diferencia del resto de grafos, este gráfico contiene datos de pertenencia a bancos en el periodo 1854-1922. Esto se debe a que buena parte de estas sociedades estuvieron antes y después de la banca libre reseñada anteriormente. Parte de los dueños de estos bancos también se verían involucrados en la formación de empresas. La tradición de los nombres y las actividades se reflejó en los datos encontrados.

13 Se sugiere que el pertenecer o hacer parte de la composición accionaria de un banco es también una relación comercial. Es posible hacer este supuesto porque los bancos de este tiempo firmaban escrituras que difícilmente les permitían vender o especular con sus acciones en estas actividades.

14 Esta limitación es importante puesto que un accionista con una mayor capacidad monetaria podría ejercer una gran influencia en las decisiones de la sociedad comercial. No obstante, el hecho de formar parte de varias asociaciones se toma como variable explicativa de la cantidad de dinero que posiblemente tendría el mencionado accionista.

tiempo\&economía Vol. 4 N. ${ }^{\circ} 1$ - I semestre de 2017 
Gráfico 2. Red de los propietarios de bancos antioqueños (1880-1930)

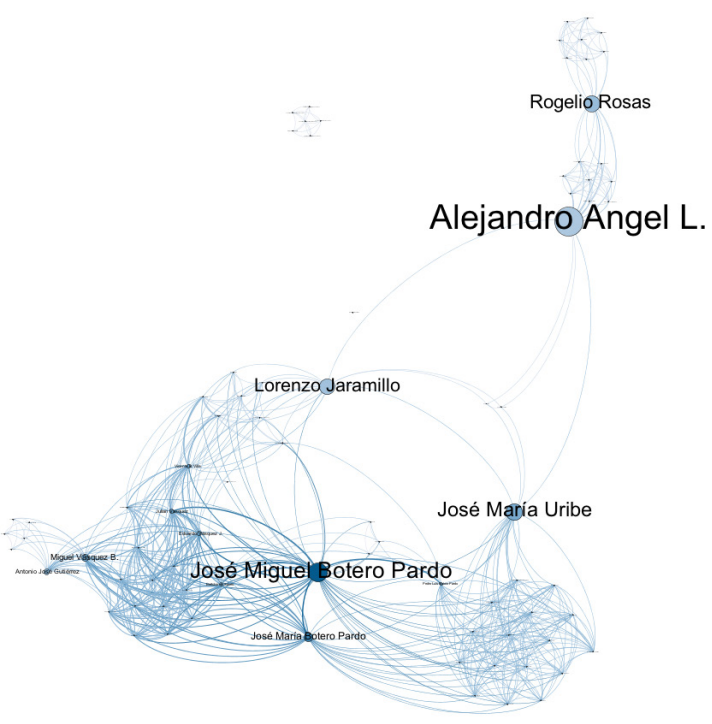

Fuente: elaboración propia.

El grafo contiene tres clústeres: uno de ellos no conectado es el correspondiente a Restrepo y Compañía, mientras que el otro corresponde al Banco de Medellín. En el esquema, los colores indican al más intenso con mayor grado ${ }^{15}$, mientras que el más tenue tiene uno menor. Para este caso, el actor con mayor cantidad de conexiones es José Miguel Botero Pardo, perteneciente a la firma Botero Arango, que estaba prácticamente en todas las entidades bancarias de este tiempo. El segundo actor en relevancia según grado es José María Botero Pardo, hermano de José Miguel Botero; la diferencia entre los dos hermanos es que uno de ellos, además de hacer negocios con la sociedad comercial de la cual hacía parte, también los hacía en su propio nombre.

El tamaño del nodo indica la medida de vector propio de centralidad ${ }^{16}$. Para el caso del gráfico 2, esta medida indica a un actor que, pese a no tener un alto grado, es el que mejor podría pasar información a lo largo de la red; por lo tanto, se infiere que tendría una mayor diversificación en las empresas más importantes, pero no necesariamente en todas. Para este caso, dicho actor es Alejandro Ángel L. De forma algo coloquial, se podría decir que si uno quisiera enterarse de los negocios más rentables, la persona que tenía un mejor conocimiento de esta información era este último.

15 Se define grado como la cantidad de aristas o relaciones que posee un actor.

16 La medida de vector propio de centralidad es la más fina en cuanto a medición de intermediación, puesto que no solo tiene en cuenta el peso de los nodos cercanos a este, sino también aquellos que, pese a no tener conexión directa, sí lo están con otros a quienes este se conecta. Puede decirse, entonces, que un actor de alto valor era quien hacía de forma más eficiente sus conexiones, puesto que no necesitaba conectarse con muchas personas dentro de la red, sino con aquellas que estaban mejor ubicadas. (Bonacich, 1987). 
Estos resultados pueden variar debido a la falta de información acerca de ciertas sociedades, pues muchas de estas aparecen como partes firmantes en la conformación de bancos o con capitales invertidos, pero no se encuentra la conformación completa de la sociedad, por tanto se tiene información parcial de los miembros y sus posibles conexiones.

Es importante mencionar que dentro de esta red no solo se encontraron nombres de personalidades pertenecientes al círculo social antioqueño, sino también personalidades de otras zonas del país, como Nemesio Camacho, empresario bogotano (Dávila, 2003). Lo anterior evidencia que los bancos antioqueños fueron alternativas de inversión visibles en otras zonas del país.

\section{Banqueros empresarios}

A diferencia de la red anterior, en este apartado se revisan aquellos que siendo banqueros, decidieron invertir en la formación de empresas.

En el gráfico 3 se observa una gran red con algunas diadas ${ }^{17}$, que no son casi visibles. Hay 94 nodos y 630 aristas, siendo esta la más grande en número de integrantes (nodos) y relaciones (aristas). Lo anterior se puede atribuir a que casi todos los banqueros que al mismo tiempo eran empresarios estaban relacionados con la red y con un mismo gran grupo. Se observa, por ejemplo, que los Restrepo se hallaban separados de los otros bancos en el grafo 2, pero en el grafo 3 se encuentran bien posicionados. Justamente Marcelino Restrepo, representante de la casa comercial Marcelino Restrepo y Cía., tiene fuertes lazos comerciales con Eduardo Vásquez, quien a su vez se comporta como banquero y está entre los cinco más importantes en la red de propietarios de bancos. Esto sugiere que algunos grupos que no tenían conexiones en el desempeño de su actividad principal, sí podían relacionarse para llevar a cabo otras iniciativas.

Gráfico 3. Grafo de empresarios que al mismo tiempo se desempeñaban en actividades bancarias

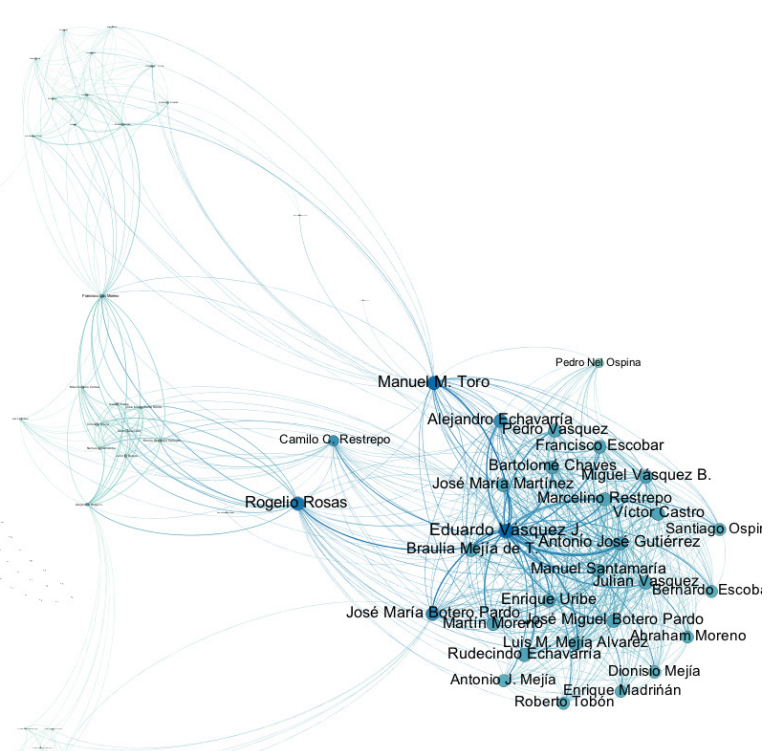

Fuente: elaboración propia.

17 Para mayor claridad acerca de este concepto, ver Anexo1. 
De manera similar al gráfico anterior, la intensidad del color está relacionada con el grado del agente. Por tanto, aquel con mayor grado en la red tiene un tono más oscuro. En este caso, el actor con estas características es Eduardo Vásquez Jaramillo; a él le sigue en puntuación Manuel M. Toro. En el cálculo de vector propio de centralidad se encuentra que estos personajes también muestran las más altas puntuaciones. Se puede suponer, entonces, que aquellos nombres con las puntuaciones más altas tienen las mejores posiciones en la red posibles, debido a que tienen mayor alcance con las relaciones que poseen.

Se debe señalar que a diferencia del caso de la industrialización alemana, la cual vio en los bancos su forma más ágil de financiar el proceso de constitución de una gran parte de su industria pesada (Fohlin, 1998), aquí solo se encontraron dos casos en los cuales aparecen los bancos como "dueños" de las empresas: el Banco de Sucre y el Banco Popular de Medellín. Así mismo, vale la pena subrayar que casi todas las participaciones de banqueros se hacen de manera individual; esto quiere decir que la persona, además de tener acciones en un banco, también tiene acciones en las empresas. Solo hay un caso en el que se encuentra que la participación en bancos (y por tanto una participación indirecta) da un alto nivel de importancia: este es Rogelio Rosas, quien nunca invirtió de manera directa en las empresas, pero era propietario de acciones en el Banco de Sucre y el Banco Republicano. Estas entidades, a su vez, tuvieron acciones en empresas con un gran número de asociados, haciendo que Rogelio Rosas tenga un alto nivel de importancia (según la métrica empleada en la metodología) y, de paso, muestre un alto grado de diversificación en la red.

Cabe anotar, por último, que hay relaciones de coincidencia de un mismo grupo de personas en relacionamientos, debido que en esta red los bancos son inversionistas directos, no se esclarece si las decisiones de inversión se hacían con la aprobación de todos los socios o no. Por lo tanto, no se sabe si esas coincidencias de personas en diferentes empresas se hacía por decisión propia o de unos pocos que manejaban la propiedad de bancos.

\section{El café (agropecuario)}

En cuanto al sector cafetero, se agrupó toda la parte agropecuaria en un solo ramo, puesto que los grandes hacendados ${ }^{18}$ (también con el ánimo de diversificar) no solo sembraban café, sino también cacao, caña y maíz, entre otros. A su vez, están los que en su afán por abastecer productos consumidos en las minas, tenían levante de ganado bovino y porcino; por lo que hacer una separación específica de ellos es muy difícil.

Esta red muestra agentes que hacen parte del sector agropecuario (con las características mencionadas anteriormente) y que, entre personas del mismo grupo, tienen relaciones comerciales (como hacer parte de una misma empresa, por ejemplo). El gráfico 4 muestra el grafo de las relaciones encontradas en las industrias antioqueñas, pero solo entre personas pertenecientes al ramo agropecuario.

Los agentes más importantes son Alejandro Echavarría Isaza y Eduardo Vásquez J., siendo el primero el que tiene un mayor grado. De nuevo, los nodos con tonos más oscuros tienen mayor grado, mientras que los más claros tienen un grado menor. Por otro lado, al medir el vector propio de centralidad, se encuentra que Alejandro Echavarría de nuevo tiene el mayor valor.

18 Dueños de grandes haciendas dedicadas a diversos tipos de producción agropecuaria (Kalmanovitz, 2003). 
Gráfico 4. Red de personas con relaciones comerciales que se pueden etiquetar como dueños de fincas o con ganancias en el sector agropecuario

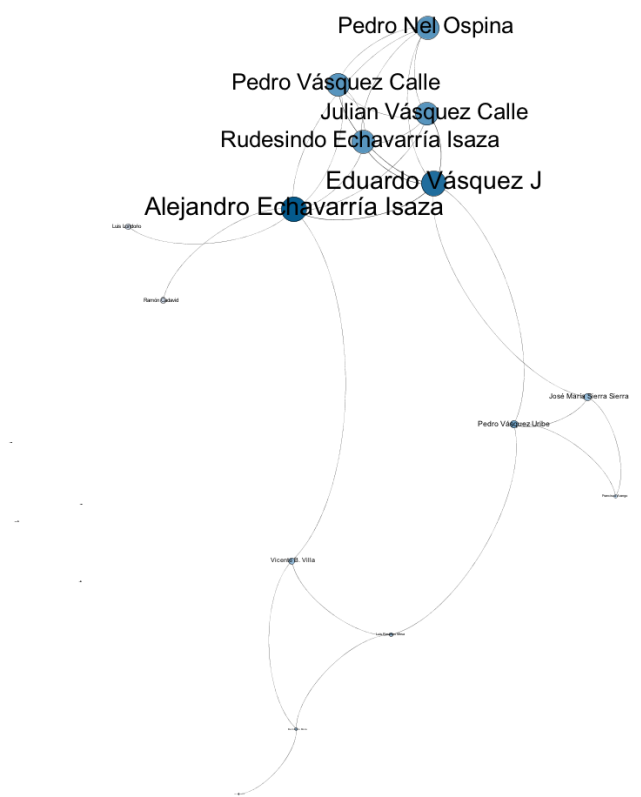

Fuente: elaboración propia.

Esta red tuvo una de las bases con mayor cantidad de agentes descartados ${ }^{19}$, por lo que no es posible decir que el número de hacendados analizados fuera insuficiente. Los nombres de hacendados encontrados en la bibliografía no pudieron ser relacionados dentro de las escrituras de constitución de las empresas. Este hecho hace pensar que para algunos hacendados la industrialización no era una alternativa interesante para diversificar.

Aquí se encuentran empresarios relacionados con las minas como Eduardo Vásquez, Pedro Vásquez Calle y su hermano Julián Vásquez Calle. Estos tenían un importante negocio que consistía en surtir productos de primera necesidad (en términos de alimentación) a aquellos que trabajaban en las minas, estableciendo de esta manera casi un monopolio alrededor de la venta de productos alimenticios en estos lugares. Por otra parte, el caso de los Ospina (Pedro Nel Ospina) es muy especial porque fue una de las familias que impulsó en gran medida la siembra de café en el suroeste antioqueño. El apellido aún hoy en día es sinónimo de café. De hecho, al revisar las redes parentales, es posible establecer que Pedro Nel Ospina ya estaba casado con Carolina Vásquez, hija de Eduardo Vásquez J.; esto puede mostrar que la relación entre estos individuos era más cercana al parentesco que a la de confianza a la hora de hacer negocios ${ }^{20}$.

19 Como se mencionó en la introducción, se tomaron los nombres de los actores en la bibliografía cuando se pudiera establecer su pertenencia a alguno de los sectores referenciado. En otras palabras, hubo muchos nombres mencionados en histobiografía a los que no se les pudo encontrar una relación con la formación de industrias. El sector agropecuario fue uno de los que en la recolección de la información tuvo mayor cantidad de actores, pero la mayoría de ellos fueron descartados.

20 Un ejemplo similar se encuentra en el trabajo de Padgett (1994), donde se muestra la importancia de las conexiones familiares en los negocios durante el periodo del renacimiento en Florencia.

tiempo\&economía Vol. 4 N. ${ }^{\circ} 1$ - I semestre de 2017 
Se habría esperado que uno de los actores con una alta puntuación en grado para este grafo fuera Bernardo Mora Mesa, quien es reconocido por su trabajo en la fundación de Coltabaco y su actividad en otras industrias. En parte, esto muestra que no formaba parte del mismo grupo de inversión, o como se diría coloquialmente, no era de "la rosca" de los Vásquez y los Ospina.

\section{Comercio}

Desde la colonia, el comercio es un ramo en el que se han destacado con mucha frecuencia los antioqueños: al tener oro, eran los únicos capaces de tranzar con el exterior pese a que estas actividades no contaban con el visto bueno de las autoridades debido a que se hallaban fuera del control español, tal y como lo señalan Brew (1977) y Botero (2003).

Botero (2003) sugiere que parte de los primeros intentos de industrialización provinieron de iniciativas en los patios de las casas, puesto que en tiempos de la Primera Guerra Mundial era muy difícil conseguir ciertos productos de uso diario. Algo común que se encuentra en las biografías de algunos industriales es que luego de viajar por el exterior y ver toda clase de adelantos, llegaban al país con la intención de reproducir y vender aquellos productos que vieron (Botero, 1996). A su vez, muchos comerciantes tomaban estos productos novedosos y los reproducían en sus lugares de origen.

En el siguiente grafo se muestran aquellos actores que, siendo comerciantes, también actuaban como empresarios.

Gráfico 5. Relaciones empresariales entre comerciantes que al mismo tiempo hacían parte de la industria

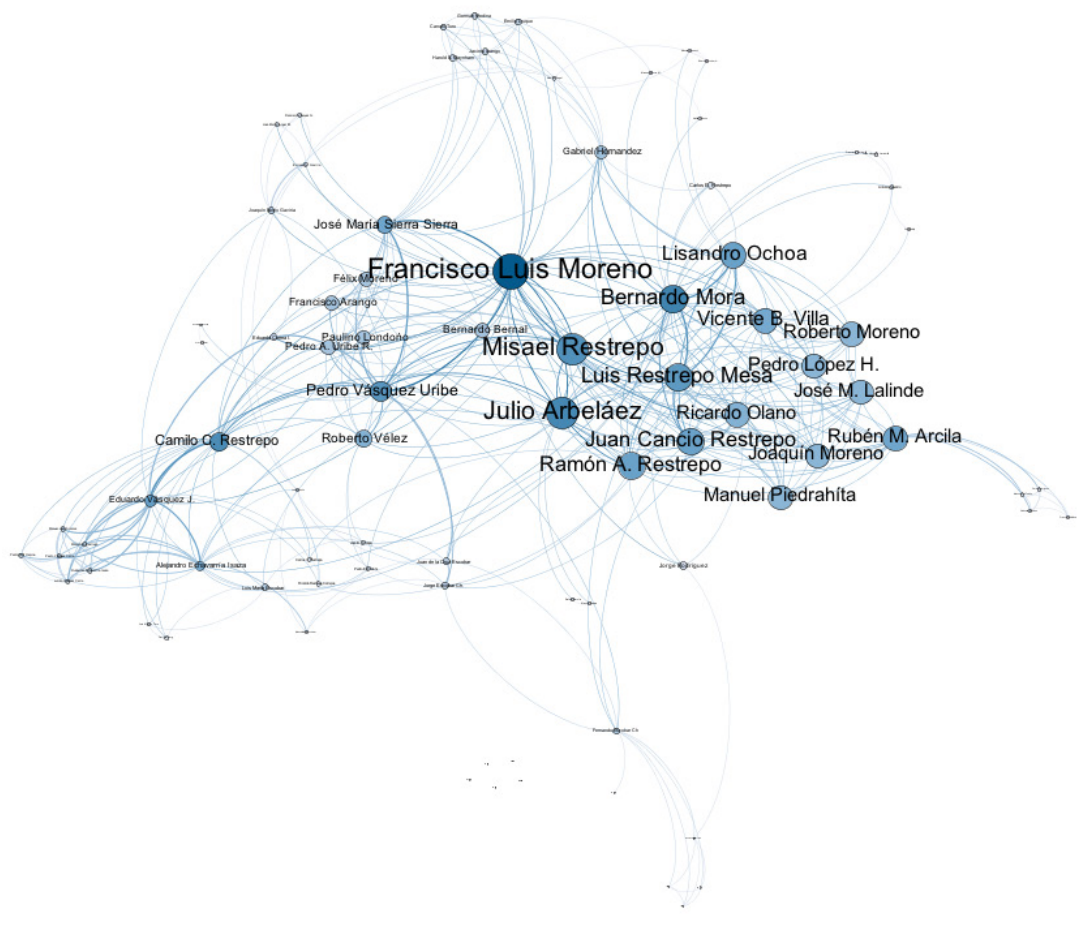


En el gráfico 5 el tono más oscuro muestra las personas con más alto grado ${ }^{21}$, mientras que los tonos claros representan a las personas con menor grado. De igual forma, las medidas de vector propio de centralidad están señaladas por el tamaño de los nodos. En este grafo, el actor con mayor grado es Francisco Luis Moreno, mientras que el segundo es Bernardo Mora Mesa. Desde el punto de vista de vector propio de centralidad, el actor con mayor puntaje de nuevo es Francisco Moreno, mientras que el segundo lugar lo ocupa Julio Arbeláez.

Una explicación que podría dar cuenta de la forma tomada por este grafo se encuentra en las afiliaciones partidistas de los comerciantes, las cuales también jugaban un papel importante a la hora de hacer negocios. A pesar de que existía una tregua entre ambas partes para no hacer la guerra, no había la confianza suficiente para hacer negocios ${ }^{22}$. Estos pequeños grupos ejercían su producción en un taller y solo contaban con un punto de venta. En esta cadena, los vendedores de la mercancía solían, en parte, ser los mismos dueños de las empresas que las producían. Estos hechos hacen aún más difícil el rastreo de los demás propietarios y mucho menos probable que se puedan asociar con algún grupo o comunidad.

\section{Red completa de empresarios}

La red de todos los empresarios cuenta con más de 7.000 aristas y compila todas las relaciones en la formación de empresas analizadas anteriormente. Dichas relaciones podían ser de dos formas, como se mencionó anteriormente: de tipo directo si la inversión se hacía a nombre propio y de tipo indirecto si se hacía a nombre de una sociedad a la que pertenecía la persona. Ambas relaciones se verán reflejadas de la misma manera en el grafo.

El gráfico 6 muestra el grafo de la mencionada red. Se puede ver que hay un gran grupo y algunos clústeres, incluso algunas diadas y triadas; pero la cantidad de estas es marginal al lado de la gran conexión que se encuentra en el resto del grafo ${ }^{23}$. Curiosamente se observa que la mayor cantidad de relaciones que se presentan son débiles ${ }^{24}$, mientras que las más fuertes se hallan fuera de la zona que tiene la mayor concentración de nodos con alto grado. Cabe mencionar que aquí se resalta un aspecto tratado usualmente en teoría de redes: las relaciones más débiles son en realidad las más fuertes, tal y como lo explica Granovetter (1983).

En un análisis detallado de los actores, Francisco Luis Moreno es quien tiene mayor cantidad de conexiones. Al analizar las relaciones con pesos, el actor con más conexiones de ese tipo es Enrique Moreno. Al revisar la medida de vector de centralidad propio, este muestra de nuevo que el actor con mayor puntuación es Francisco Luis Moreno.

21 El grado es de tipo binario, por lo tanto no se tiene en cuenta si un comerciante coincidió con otro en la conformación de más de una empresa. Esto mismo aplica para los grafos anteriores en cuanto a la característica de color del nodo.

22 Este argumento se deduce de la misma bibliografía, la cual en ocasiones señalaba las inclinaciones políticas de los actores.

23 Un análisis de clústeres o comunidades podría servir para estudiar, de manera mucho más exhaustiva, las relaciones presentadas en esta red. Dicho análisis se deja para estudios futuros.

24 En este contexto, una relación débil es aquella que tiene un peso igual a 1. Esto quiere decir que el empresario en cuestión es socio con otro actor en solo una empresa.

tiempo\&economía

Vol. 4 N. ${ }^{\circ} 1$ - I semestre de 2017

p. 71 
Gráfico 6. Grafo de la red de empresarios antioqueños en el periodo 1880-1930

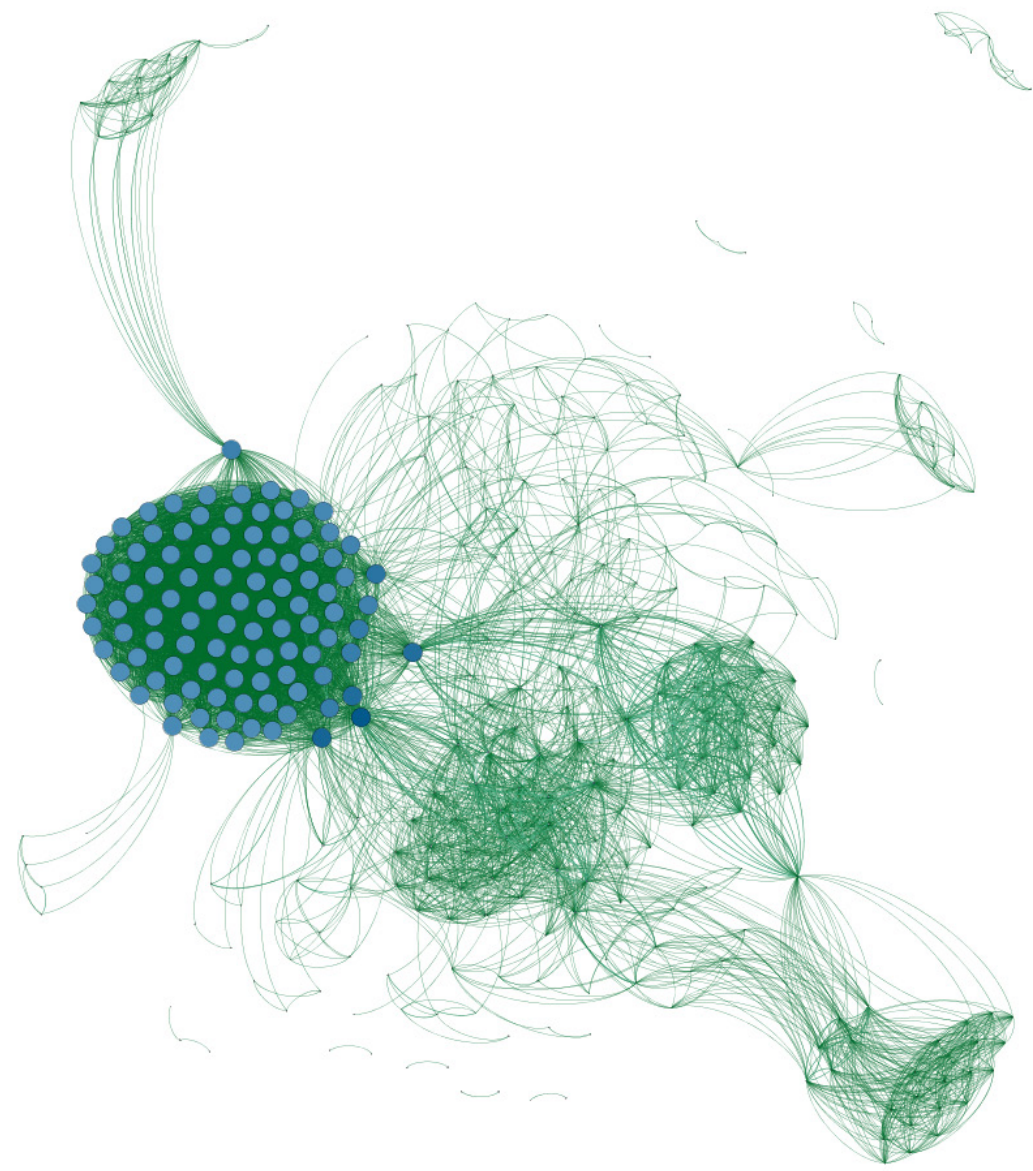

Fuente: elaboración propia.

De este modo, puede verse la alta influencia que los comerciantes ejercieron en este periodo sobre las empresas, puesto que aquellos agentes que tuvieron altas puntuaciones en comercio también repitieron este fenómeno en la red completa. Se puede apreciar la existencia de algunos clústeres, pero estos son mínimos cuando se comparan con la longitud y el tamaño de la gran red que está totalmente conectada. Estos clústeres representan grupos económicos que, pese a no estar muy conectados con sus iguales, sí lo están con otros grupos; en otras palabras, estos grupos funcionaban muy bien como enlaces para otros grupos de inversión o servían como receptores finales de los recursos provenientes de estos otros grupos, los cuales invertían finalmente en nuevas empresas. Posiblemente un análisis más detallado en agujeros estructurales a este fenómeno pueda demostrar si estos clústeres funcionaron como puentes en la distribución de capitales.

En el gráfico 6 se encuentran por lo menos seis grupos definidos; uno altamente conectado y los otros medianamente conectados. El grafo también permite ver que en ocasiones un actor sirve de enlace para conectar una comunidad que, en caso de no existir este agente, estaría totalmente aislada. Esto puede explicar por qué no hay homogeneidad en cuanto a la 
participación de los agentes en la financiación de la industrialización. Visto de otro modo, es posible decir que solo unos pocos fueron participantes directos en la fundación de la mayoría de las empresas.

\section{Resultados y discusiones}

Las estadísticas no dicen mucho si se revisan de manera aislada, pero cuando se estudian en conjunto se encuentra que el comercio fue uno de los grupos con más industriales, seguido de los banqueros. Prácticamente ambos grupos tenían la misma cantidad de personas aportantes. Es pertinente recordar que al no tener datos exactos de los montos aportados por cada uno de estos grupos, se esté pasando por alto información relevante en cuanto a la cantidad aportada.

Tabla 2. Estadísticas de las redes en análisis por actividad económica

\begin{tabular}{|c|c|c|c|c|c|}
\hline Medidas & Bancario & Agropecuario & Minero & Comercial & Urbanización \\
\hline Nodos & 94 & 23 & 15 & 95 & 19 \\
\hline Aristas & 630 & 30 & 19 & 402 & 30 \\
\hline Grado Medio & 13,4 & 2,6 & 2,5 & 8,5 & 3,2 \\
\hline $\begin{array}{c}\text { Grado Medio con } \\
\text { Pesos }\end{array}$ & 24,22 & 4,1 & 4,5 & 10,3 & 3,7 \\
\hline Diámetro de Red & 6 & 4 & 1 & 4 & 5 \\
\hline \begin{tabular}{c} 
Densidad de Grafo \\
\hline $\begin{array}{c}\text { Longitud Media } \\
\text { de Camino }\end{array}$
\end{tabular} & 0,144 & 0,119 & 0,181 & 0,09 & 0,175 \\
\hline
\end{tabular}

Fuente: elaboración propia.

El grupo con mayor número de conexiones totales es el bancario, el cual tiene un $36 \%$ de diferencia con respecto a los comerciantes. Así, se deduce entonces que alguien que haga parte de un banco se asocie con mayor facilidad con alguien que pertenezca al mismo grupo. Dicho señalamiento puede dar indicios de la confianza que había en este sector económico con sus iguales, lo que se manifiesta en la cantidad de conexiones por actor que se muestra en esta red, la cual es mayor que la mostrada en las otras redes estudiadas.

En el análisis del grado medio con pesos se encuentra que los pesos pueden llegar a duplicar el grado medio, esto a causa de que las relaciones comerciales no se limitaban exclusivamente a la empresa en la que los actores aparecían como socios. El único caso en que los pesos no duplican el grado medio es la red de comerciantes, probablemente porque muchos de estos solo tenían acciones en una empresa (pues vendían sus productos en sus propios negocios).

En cuanto a la densidad de grafo, los grupos que mostraron un mayor valor fueron la minería, la urbanización y los bancos. Esta medida permite conocer qué tan comunicada se encuentra una red. Para los tres grupos mencionados, una posible explicación se deriva del uso de un bien común en las tres actividades: el oro. El uso de este bien requería de un cierto nivel 
de confianza entre los actores, lo que los llevaba a mantener una comunicación permanente, fortaleciendo el vínculo que existía entre unos y otros. Por otro lado, el grupo que mostró una densidad menor es el de los comerciantes. Esto se explica por los requisitos para ejercer el oficio: no requiere de grandes cantidades de capital y la confianza, aunque necesaria, no es imprescindible. Es por ello que las relaciones entre actores no eran tan fuertes.

La conectividad general de un grafo también puede medirse por medio de la longitud de camino. De manera general, la medida ayuda a establecer qué tan cerca está un agente del otro a la hora de hacer negocios o generar influencias. Aquí se destaca que los comerciantes de nuevo sean los que tienen el valor más alto, reforzando la idea de que este grupo es el menos cohesionado de todos.

Revisando el comportamiento de los banqueros se encuentra que, pese a ser el grupo con la menor cantidad de agentes, estos están estrechamente relacionados con otras actividades. Lo anterior permite concluir que los banqueros fueron grandes diversificadores del riesgo. Así mismo, por ser el grupo más cohesionado, muestra que interactuaron en varias actividades con el fin de lograr una mayor circulación del dinero. Una posible razón para que esto ocurriera es la unión y confianza que existía entre banqueros, hecho que les permitía comunicar con mayor seguridad la información que tuvieran a través de la red. Por lo tanto, es posible ver que los capitales no surgieron de manera espontánea (pasando directamente por los bancos), sino que provinieron también de otras actividades (esto suponiendo que las otras actividades se desarrollaron antes que la industrialización).

La gran conexión de los industriales con el resto de los grupos muestra el carácter central de esta actividad, es decir que en el periodo estudiado era la actividad que congregaba la mayor cantidad de inversionistas.

En cuanto a estos análisis, es necesario hacer una salvedad: no se pudo establecer una causalidad clara sobre si los recursos de otras actividades fueron a pasar directamente a las industrias o si los excedentes de las ganancias industriales engrosaron otras actividades como la urbanística. En algunos casos el notario dejaba constancia en la escritura de la empresa la actividad a la que se dedicaban los constituyentes de la misma, por lo que de este modo se puede suponer que esos agentes tenían una actividad base de la que obtuvieron recursos que luego pasarían a la industria.

Otra limitación en el desarrollo de este estudio fue la falta de conocimiento del tipo de relación que existía detrás de un vínculo empresarial; es decir, que una persona podría tener algún lazo de amistad con otra, pero esto no implicaba que su vínculo fuera más allá. Del análisis se puede inferir que debía existir algún nivel de confianza entre los agentes como para poner capitales en riesgo; aun así, no se puede decir si esta relación tenía otro tinte. Además, al carecer, por ejemplo, de información acerca de filiaciones políticas, no se pudo establecer el nivel de cercanía que existía entre las personas. Lo único que se sabe es que había algún tipo de afinidad y cercanía, por lo menos a la hora de firmar una escritura de constitución de una empresa. 


\section{Conclusiones}

Este análisis contestó indirectamente a la pregunta inicial: ¿cómo se juntaron los capitales que financiaron la industrialización antioqueña? Las limitaciones existentes en los datos no permitieron establecer si los caficultores fueron los mayores financiadores de la industrialización antioqueña, pero sí se pudo establecer que no fueron ni los únicos ni los más importantes. Al revisar una a una las actividades económicas, se estableció que había más relaciones entre unas actividades que en otras, lo que se evidencia en las diferentes medidas hechas a las redes que surgieron durante el análisis.

El grupo que presenta mayor conexión entre sí es el bancario, probablemente porque está más acostumbrado a tratar entre sus iguales, dado el riesgo de su actividad. En esta red se observan algunos lazos parentales que se ven reforzados en otras actividades económicas. Incluso sociedades totalmente separadas como bancos (en su conformación), se encuentran con otros grupos en otras actividades. Es de señalar también que el ser reconocido como banquero no implica que sea importante como industrial; un ejemplo de ello es la sociedad de los Botero, la cual se destacaba más en sus negocios bancarios, teniendo una pobre intervención en la formación de lazos con industriales. Lo anterior sugiere que no todos los recursos que financiaron la industrialización antioqueña pasaron por los bancos.

En el sector agrícola se encuentra como nodo central a Alejandro Echavarría, el reconocido empresario fundador de la empresa Coltejer y también heredero de la fortuna de Rudesindo Echavarría. Al ser uno de los más importantes comerciantes de la época (su sociedad comercial estaba presente en casi todas las empresas importantes), fue una gran influencia en la formación de empresas. Por lo demás, las estadísticas muestran a los empresarios con algún tipo de negocio agropecuario como un grupo poco conectado consigo mismo y también con otros sectores.

Visto esto, es posible afirmar que los capitales que hicieron posible la industrialización antioqueña provinieron de actividades diversas y no exclusivamente del café. Es problemático enunciar exactamente cuál actividad fue la impulsadora real de este proceso industrial ya que, como se mencionó líneas arriba, no se contó con los valores monetarios de cada una de las inversiones. Lo que sí se puede establecer es que el número de inversores que eran simultáneamente comerciantes y banqueros era mayor. La evidencia encontrada con el estudio de redes permite reconocer grupos que formaron capital en una actividad específica y que se conectan con otros al momento de realizar actividades empresariales. Las redes de familia suelen ser un factor importante a la hora de hacer negocios, pero no son el único lazo existente en la conformación de empresas. La única explicación sobre la existencia y prueba de este fenómeno es la confianza existente entre diversos agentes que "pusieron en juego" sus capitales, tratando así de diversificarse en sus actividades económicas. Esta confianza solo era posible porque las relaciones sociales de este periodo se predeterminaban a través de contratos escritos y de palabra, legitimando el hecho de que los oportunistas fueran señalados si no cumplían.

La hipótesis de que un grupo económico más cohesionado impulsara la industrialización con más fuerza que otro no resultó ser cierta, o por lo menos, no de manera contundente. Si se evalúan los casos de banqueros, se puede decir que para este grupo sí se valida la hipótesis. Pero al verla desde la perspectiva de los comerciantes, la hipótesis pierde todo su peso, debido 
a que este grupo ostenta el valor más bajo de densidad de red y el más alto en longitud media de camino.

La razón para que los comerciantes hubiesen tenido tanto conocimiento de lo que pasaba con la industria se debe a la naturaleza de su actividad, que los obligaba a estar en contacto continuo con las personas y a estar al tanto de la información y de las necesidades de capital de otros. Otra razón es que muchos de ellos fueron los primeros en arriesgar sus capitales al poner en los solares de sus casas lo que pudieron ser las primeras máquinas. Por ejemplo, la persona más notoria en la red, Francisco Luis Moreno, no tenía a su cargo una sola empresa, aunque sí formó parte de las juntas directivas de varias instituciones importantes de la época (fuera de la construcción del teatro Lido de Medellín). Este hecho demuestra la capacidad de diversificación y eficiencia de Moreno a la hora de hacer negocios, puesto que probablemente estaba en una mayor cantidad de empresas, que a su vez eran las que mejor comportamiento tenían, y, por tanto, era quien debía tener mejor conocimiento del funcionamiento de estas durante la industrialización.

Las diferentes características de los grupos compuestos por banqueros industriales y comerciantes industriales muestran de manera intuitiva que el comercio y los bancos estuvieron más cerca de la industrialización de lo que estuvo el sector agropecuario; hecho bastante diferente a lo encontrado en la literatura, que siempre mostró al café como el principal impulsor de la industrialización.

\section{Referencias}

Álvarez, A., \& Timoté, J. (2011). La experiencia de banca libre en Bogotá (1871-1880): de la utopía económica el pragmatismo frente a la crisis. Documentos CEDE. 2011-32. Ediciones Uniandes.

Álvarez, V. (2003). De las sociedades de negocios al «Sindicato Antioqueño». Un camino centenario. En C. Dávila (Comp.), Empresas y empresarios en la historia de Colombia. Siglos XIX-XX. Una colección de estudios recientes. Bogotá: Editorial Norma y Ediciones Uniandes.

Arango, M. (1977). Café e industria 1850-1930. Bogotá: Carlos Valencia Editores.

Badia-Miró, M., Blasco-Martel, Y., Lozano, S., \& Soler, R. (2012). Redes sociales y negocios. La red de inversión del Banco de Barcelona en la economía catalana a mediados del siglo XIX. Investigaciones de Historia Económica - Economic History Research, 52(3), 493-515.

Bonacich, P. B. (1987). Power and centrality: a family of measures. American Journal of Sociology $92,1170-1182$

Botero, A., \& Alberto, S. (2006). Medellín. República de Colombia (segunda edición). Medellín: Instituto Tecnológico Metropolitano.

Botero, F. (1996). Medellín 1890-1950: Historia Urbana y juego de intereses. Medellín: Editorial Universidad de Antioquia.

Botero, F. (2003). La industrialización en Antioquia, génesis y consolidación 1900-1930. Medellín: Hombre Nuevo Editores. 
Botero, M. (2007). La ruta del oro: una economía primaria exportadora : Antioquia, 1850-1890. Medellín: Universidad Eafit.

Brew, R. (1977). El desarrollo económico de Antioquia desde la independencia hasta 1920. (A. M. López, Trad.) Bogotá: Talleres Gráficos del Banco de la República.

Correa, J. (2009). Banca y región en Colombia, 1850-1880. Revista de Economía Institucional, $11(20), 15-44$.

Cuervo, L. M., \& González, L. J. (1997). Industria y ciudades en la era de la mundialización (19801991). Un enfoque socioespacial. Bogotá: Tercer Mundo Editores.

Echavarría, E. (2008). Crónicas e historia bancaria de Antioquia. Medellín: Instituto Tecnológico Metropolitano.

El Boletín Industrial, Bogotá (1902-1905).

El Espectador, Medellín (1887-1904).

Fohlin, C. (1998). Relationship Banking, Liquidity, and Investment in the German Industrialization. The Journal of Finance, 53(5), 1737-1758.

Gerschenkron, A. (1970). Atraso económico e industrialización. Barcelona: Ediciones Ariel.

Furtado, C. (1976). La Economía Latinoamericana: Formación histórica y problemas contemporáneos. México: Siglo Veintiuno Editores.

Granovetter, M. (1983). The Strength of Weak Ties: A Network Theory Revisited. Sociological Theory, 1, 201-233.

Granovetter, M. (2005). The Impact of Social Structure on Economic Outcomes. Journal of Economic Perspectives, 19 (Winter), 33-50.

Grupo de Historia Empresarial EAFIT. (2006). Fuentes documentales para la historia empresarial. Tomo I, Siglo XIX en Antioquia. Medellín: Fondo Editorial Universidad Eafit.

Grupo de Historia Empresarial EAFIT. (2013). Fuentes documentales para la historia empresarial: la industria de Antioquia, 1900-1920. Medellín: Fondo Editorial Universidad Eafit.

Huidobro, M. A. (2012). Breve historia de la banca de desarrollo mexicana. Análisis Económico, $27(65), 171-206$.

Kalmanovitz, S. (2003). Economía y nación: una breve historia de Colombia. Bogotá: Editorial Norma.

Kalmanovitz, S. (2010). Nueva Historia Económica de Colombia. Bogotá: Distribuidora y editora Aguilar.

Landes, D. (1979). Progreso tecnológico y revolución industrial. Madrid: Editorial Tecnos.

Lipset, S., \& Solari, A. (1967). Élites y desarrollo en América Latina. Buenos Aires: Paidós.

Mayor, A. (1984). Etica, trabajo y productividad en Antioquia : una interpretación sociológica sobre la influencia de la Escuela Nacional de Minas en la vida, costumbres e industrialización regionales. Bogotá: Ediciones Tercer Mundo. 
Mejía, J. (2012). Diccionario biográfico y genealógico de la élite antioqueña y viejocaldense. Segunda mitad del siglo XIX y primera del XX. Pereira: Sello Editorial Red Alma Mater.

Molina, L. (2006). Empresarios colombianos del siglo XIX. Bogotá: Ediciones Uniandes.

Montenegro, S. (2002). El arduo tránsito hacia la modernidad: historia de la industria textil colombiana durante la primera mitad del siglo XX. Medellín: Editorial Universidad de Antioquia.

Nieto, L. E. (1997). El café en la sociedad colombiana. Bogotá: El Áncora Editores.

Ocampo, J. A. (2007). Historia Económica de Colombia. Bogotá: Editorial Planeta Colombiana S. A.

Ospina, J. (1927). Diccionario biográfico y bibliográfico de Colombia. Bogotá: Editorial de Cromos.

Ospina, L. (1987). Industria y Protección en Colombia 1810-1930. Medellín: Editorial Bedout.

Padgett, J. F. (1994). Marriage and Elite Structure in Renaissance Florence, 1282-1500. Documento presentado a la Social Science History Association, Atlanta, Georgia, 14 de octubre de 1994.

Palacios, M. (1983). El café en colombia, 1850-1970. Una historia económica, social y política (segunda Edición). Bogotá, Colombia: El Colegio de México- El Áncora Editores.

Pineda, Y. (2007). Manufacturing Profits and Strategies in Argentine Industrial Development, 1904-1930. Business History, 49(2), 186-210.

Poveda, G. (1979). Dos siglos de historia económica de Antioquia. Medellín: Biblioteca Pro Antioquia.

Poveda, G. (1982). Minas y Mineros de Antioquia. En Simposio los estudios regionales en Colombia: El caso de Antioquia (1979, Agosto, 6-11: Faes, pp. 41-50). Medellín: Fondo Rotatorio de Publicaciones FAES.

Poveda, G. (1984). Minas y Mineros de Antioquia. Medellín: Departamento Editorial del Banco de la República.

Poveda, G. (2005). Historia Económica de Colombia en el Siglo XX. Medellin: Editorial Universidad Pontificia Bolivariana.

Riberio, M. T. (2004). The Origins of the Pioneer Cotton Mills in Minas Gerais, Brazil, 1868-1879: A Reassessment. Enterprise \& Society , 5 (2), 226-253.

Roldán, M. (2003). A sangre y fuego. La violencia en Antioquia, 1946-1953. Bogotá: ICANH/Fundación para la promoción de la Ciencia y la Tecnología.

Restrepo, N. (2011). Empresariado antioqueño y sociedad, 1940-2004: influencia de las élites patronales de Antioquia en las políticas socioeconómicas colombianas. Medellín: Editorial Universidad de Antioquia.

Ruhnau, B. (2000). Eigenvector-centrality - a node centrality? Social Networks, 22, 357-365.

Safford, F. R. (1963). Significación de los antioqueños en el desarrollo económico colombiano : un exámen crítico de las tesis de Everett Hagen. Evanston, Illinois: Northwestern University. 
Sastoque, E. (2014). El papel de los banqueros y comerciantes en la unificación del Estado y la Soberanía Monetaria en Colombia 1880-1931. Borrador. Tesis doctoral para optar por el título de doctor en Ciencias Sociales y Humanas de la Pontificia Universidad Javeriana.

Smith, A. (2010). Investigación sobre la naturaleza y causa de la riqueza de las naciones (Segunda Edición (ed.). (G. Franco, Trad.) México: Fondo de Cultura Económica.

Straus, A. (2011). Banques et industrie en France et en Angleterre : des années 1880 à la seconde guerre mondiale. Revue d'économie financière, 104, 35-49.

Tang, J. P. (2011). Technological leadership and late development: evidence from Meiji Japan, 1868-1912. Economic History Review , 64, 99-116.

Teicheret, P. (1961). Revolución económica e industrialización en América Latina. México: Fondo de Cultura Económica.

Tirado, Á. (2000). Introducción a la historia económica de Colombia (Vigésimo primera edición ed.). Bogotá: El Áncora Editores.

Tovar, B. (1989). La economía colombiana, 1886-1922. En Á. Tirado, Economía, Café, Industria (pp. 9-50). Bogotá: Planeta colombia editorial.

Twinam, A. (1985). Mineros, comerciantes y labradores: las raíces del espíritu empresarial en Antioquia: 1763-1810. Medellín: Fondo Rotatorio de Publicaciones FAES.

Uribe de H., M. T., \& López Lopera, L. M. (2011). Un retrato fragmentado: ensayos sobre la vida social, económica y política de Colombia -- siglos XIX y XX. Medellín: La Carreta Editores.

Valencia, A. (2003). El empresario en el antiguo Caldas (1850-1930). En C. Dávila, Empresas y empresarios en la historia de Colombia. Siglos XIX-XX. Una colección de estudios recientes. Bogotá: Editorial Norma y Ediciones Uniandes. 


\section{Anexo 1}

Siguiendo a Wasserman y Faust (2009), se usan redes sociales en un análisis porque permiten establecer de manera formal la estructura social de un grupo. En la red se pueden conocer roles, relaciones, posiciones sociales, posibles subgrupos, popularidad, separación, prestigio e importancia. Esto se puede hacer por medio de la matemática que estudia la estructura de estas redes. De esta forma, se pueden medir las estructuras y sistemas que hay en un grupo específico. Sin embargo, tener una red no implica que estén hechas las medidas, puesto que las medidas son un paso posterior a la construcción de la red.

Para este análisis es importante tener claras ciertas definiciones:

- Actores: son aquellos sobre los que se van a estudiar las estructuras. Se establece que son discretos, como parte de un grupo o una colectividad. Es de aclarar que son estos quienes conforman en realidad el conjunto sobre el cual se va a trabajar.

- Vinculo relacional: los actores usualmente están relacionados bajo vínculos sociales. De esta manera, se establece que existe alguna relación entre ambos. Esta relación puede tener sentido e incluso se puede valorar; es decir, qué tan fuerte es la relación.

- Diada: es la relación más básica entre dos actores; así mismo, es aquella que se usa para hacer todo tipo de medidas en una red. Con la adhesión de otro individuo se convierte en una triada y, con ello, se amplían las diferentes posibles relaciones. En realidad, la diada constituye el punto de partida para la formación de subgrupos y grupos.

- Red social: una red social es la suma del conjunto de posibles actores, las relaciones existentes entre los mismos y las uniones o links entre cada uno de ellos.

- Modo de una red: una red puede ser de uno o varios modos dependiendo de la cantidad de conjuntos entre los cuales se agrupen los actores. En esta investigación la red que se tiene es una red a un modo.

Una buena manera de formalizar matemáticamente el tema de redes sociales es por medio de la teoría de grafos. En estos modelos de red también se emplean aspectos de álgebra y de sociometría. Desde el punto de vista de la teoría de grafos se define $N$ como el conjunto de nodos en la red, que para nuestro caso serán los actores como:

$$
N=\left\{n_{1}, n_{2}, n_{3}, n_{4}, \ldots, n_{g}\right\}
$$

Con $g$ se define el número de actores en la red; así mismo, para este caso existe una relación entre $n_{i}$ y $n_{j}$ teniendo en cuenta que el primer actor es relativo al segundo actor. Así, existe un vínculo entre $n_{i}$ y $n_{j}$. Este vínculo está en el conjunto de los $L$, de tal forma que este conjunto se describe como:

$$
L=\left\{l_{1}, l_{2}, l_{3}, \ldots, l_{h}\right\}
$$


Como se puede ver, hay $h$ vínculos entre los actores en teoría de grafos. Cuando hay una unión entre un nodo y otro se dice que hay un arco, por lo tanto, en una red con $h$ vínculos también hay $h$ arcos. Estos arcos pueden tener atados a cada uno de ellos un valor que los identifica o "pesa" en la relación:

$$
V=\left\{v_{1}, v_{2}, \ldots, v_{L}\right\}
$$

De manera general, se dice que un grafo está compuesto por $(N, L, V)$. Casi nunca se tienen en cuenta relaciones con el autor mismo y en este trabajo tampoco se tuvieron en cuenta. Otro supuesto bajo el que se trabaja es que las relaciones son reciprocas y en consecuencia tendríamos

$$
\left(n_{i} \rightarrow n_{j}\right)=\left(n_{j} \rightarrow n_{i}\right)
$$

Por otro lado, se puede decir que un grafo como máximo va a tener $\frac{\boldsymbol{g}(\boldsymbol{g}-\mathbf{1})}{\mathbf{2}}$ vínculos. Si bien es cierto, se pueden hacer diferentes grupos de vínculos, llamados relación. En un grafo pueden existir numerosas relaciones. Cuando una relación es direccional y valuada tiene sentido hablar del conjunto $X$, de tal forma que los elementos $x_{i j}$ son el valor del vínculo entre $n_{i}$ y $n_{i}$ donde $i \neq i$. Para esta investigación, en algunos grafos se tomaron relaciones valuadas, lo que quiere decir que los actores se encontraban más de una vez, pero hemos de resaltar que todos los valores del conjunto $X$, entre la investigación, son subconjunto de los enteros positivos. Así mismo, cuando se habla de una relación específica, se toma un subíndice para indicar a qué relación pertenece.

Se define como subgrafo a un conjunto en el que los nodos hagan parte de un grafo y los vínculos también hagan parte de los vínculos del grafo.

Se define como grado nodal al número de líneas que inciden en un nodo, de tal forma que un nodo con un alto grado nodal es uno con muchas relaciones. A partir de esta medida, se pueden derivar otras que dan información del grafo, como el grado promedio:

$$
\bar{d}=\frac{\sum_{i=1}^{g} d\left(n_{i}\right)}{g}
$$

Estas medidas del grado promedio para relaciones con pesos puede variar, dado que cuando la relación de un nodo (o la línea que incide en este) tiene un peso, su grado aumenta. Un ejemplo de ello es el de la incidencia en un nodo de 4 relaciones con valor 1 sea equivalente a dos relaciones con valor 2 . Una variación de este hecho se ve cuando el $g$ de la ecuación toma el valor de las relaciones con pesos.

Otra forma de medir si un grafo tiene o no muchas conexiones entre sí es por medio del cálculo de la densidad del grafo:

$$
\Delta=\frac{h}{g(g-1) / 2}=\frac{\bar{d}}{g-1}
$$


Se define como una caminata el pasar de un nodo al otro por medio de relaciones. Este principio fundamenta las medidas relacionadas con geodésica de la red o longitud de camino.

Una geodésica $d(i, j)$ es el camino más corto entre los nodos $n_{i}$ y $n_{j y}$ dado que la distancia es la misma desde ambos nodos $d(i, j)=d(j, i)$, se define el diámetro del grafo como la mayor distancia entre los nodos i y j como la relación entre puntos más "alejados" dentro de la red, es decir.

$$
\text { Diametro }_{g}=\max _{i} \max _{j} d(i, j)
$$

Este valor va desde 1 hasta $g-1$, siendo 1 el valor de un grafo totalmente conectado.

En los grafos valuados es mejor tomar la forma matricial de un grafo. A la hora de hacer algunos cálculos, la matriz del grafo (para el caso de una red de un modo) tiene en sus filas y columnas las relaciones existentes en el grafo:

$$
\begin{array}{cccccccc} 
& n_{1} & n_{2} & n_{3} & \cdots & n_{j} & \cdots & n_{M} \\
n_{1} & 0 & x_{12} & x_{13} & \cdots & x_{1 j} & \cdots & x_{1 M} \\
n_{2} & x_{21} & 0 & x_{23} & \cdots & x_{2 j} & \cdots & x_{2 M} \\
n_{3} & x_{31} & x_{32} & 0 & \cdots & x_{3 j} & \cdots & x_{3 M} \\
\vdots & \vdots & \vdots & \vdots & \ddots & \vdots & \cdots & \vdots \\
n_{i} & x_{i 1} & x_{i 2} & x_{i 3} & \cdots & x_{i j} & \cdots & x_{i M} \\
\vdots & \vdots & \vdots & \vdots & \ddots & \vdots & \cdots & \vdots \\
n_{N} & x_{N 1} & x_{N 2} & x_{N 3} & \cdots & x_{N j} & \cdots & x_{N M}
\end{array}
$$

Cada uno de los elementos de la matriz representa las relaciones entre cada nodo y, como para este caso se obviaron las autointeracciones, la diagonal es cero. Se aclara que los elementos $x_{i j}$ pueden tomar valores enteros y positivos. De esta forma, el cálculo del grado de un nodo sería:

$$
d\left(n_{i}\right)=\sum_{j=1}^{g} x_{i j}=\sum_{i=1}^{g} x_{i j}
$$

El cálculo de la densidad sería:

$$
\Delta=\frac{\sum_{i=1}^{g} \sum_{j=1}^{g} x_{i j}}{g(g-1)}
$$

Por otra parte, el cálculo de prominencia y centralidad en una red busca mostrar la posición que ocupa un nodo (actor) dentro de la red. En este caso, solo se empleó una medida que mostrara esto: debido a que solo importaba tener en cuenta el actor con mayor gado de centralidad, la medida que mejor ajustaba en este aspecto era la de vector propio de centralidad, desarrollada por Bonacich (1987). 
Esta medida muestra con claridad el actor que de manera más eficiente ${ }^{25}$ es capaz de conectarse de mejor forma a la red. A su vez, esta medida no captura solo la información de los nodos adyacentes, sino también la de otros nodos un poco más alejados. Para esto se tuvo en cuenta la definición de centralidad, que para el caso de esta tesis es la de intermediación. Se parte de las geodésicas que conectan $j$ y $k$. Teniendo en cuenta esto, se verifican las posibles "rutas" que comuniquen un nodo con el otro, de tal forma que se define $g_{i k}$ como el número de geodésicas que comunican los nodos. Ahora bien, si estas geodésicas incluyen algún actor $i$ que medie entre los otros dos, se define $g_{i k}\left(n_{i}\right)$ tomando la probabilidad de que esto ocurra y sumándola se tiene la centralidad de intermediación:

$$
C_{B}\left(n_{i}\right)=\sum_{j<k} g_{j k}\left(n_{i}\right) / g_{j k}
$$

Por su parte, Ruhnau (2000) sostiene que en este contexto el vector propio de centralidad parte de la suma de las adyacencias de las centralidades $c\left(v_{i}\right)$, que para este caso son las de intermediación:

$$
\lambda c\left(v_{i}\right)=\sum_{j=1}^{n} a_{i j} c\left(v_{j}\right) \quad \forall i
$$

De esta forma se resuelven los valores propios de cada nodo y de allí se obtienen los resultados de cada actor.

25 Se toma como eficiencia la capacidad de tener menores conexiones, teniendo en cuenta que cada conexión implica un costo que debe ser asumido por el actor. 